\title{
GPPS-BJ-2019-0221
}

\section{Studies on part load controlled cooling air supplies in stationary gas turbines}

\author{
Dominik Woelki \\ Chair for Aero Engines \\ Institute of Aeronautics and Astronautics \\ Technische Universität Berlin \\ Dominik.Woelki@ilr.tu-berlin.de \\ Berlin, Germany
}

\author{
Jonas Foret*, \\ Louise Dittmar, Mustafa Kanik \\ Chair for Aero Engines \\ Institute of Aeronautics and Astronautics \\ Technische Universität Berlin \\ Berlin, Germany
}

\author{
Dieter Peitsch \\ Chair for Aero Engines \\ Institute of Aeronautics and Astronautics \\ Technische Universität Berlin \\ Dieter.Peitsch@ilr.tu-berlin.de \\ Berlin, Germany
}

\section{ABSTRACT}

The design of new stationary gas turbines and development of upgrades for existing respectively is facing challenges regarding part load operation. The demands for high overall efficiency and compliance with legal requirements depend on the design of cooling air circuits among others. The design of an optimized secondary air distribution at both base load and part load as well as the consideration of different ambient conditions requires conceptual studies and hence appropriate models.

This paper introduces the holistic model of a literature based generic stationary gas turbine, which essentially couples a gas turbine performance synthesis model with a more detailed secondary air system (SAS) network model. Extended with additional models such as evaluation of blade and vane material temperatures $\mathrm{T}_{\text {mat }}$, it allows for comparative off design studies with uncontrolled and controlled turbine cooling air circuits. The presented studies here first focus on margins of $\mathrm{T}_{\text {mat }}$ with base load condition as benchmark. The subsequent exploitation of these margins is limited by the fundamental requirements of hot gas ingestion at common rim seal configurations. Either way, the reduction of cooling air at part load is beneficial in terms of fuel flow reduction: vane cooling air control results in up to $0.12 \%$ of fuel flow reduction at part load operation.

* present: Institute of Gas Turbines and Aerospace Propulsion, Technische Universität Darmstadt, Darmstadt, Germany

\section{INTRODUCTION AND OBJECTIVE}

Today's trend in energy policy demands for a high share in energy supply from regenerative sources, like wind or solar power plants. Despite of that, gas turbines will remain vital in the future to cover energy spikes. This implies changed requirements for gas turbines regarding part load operation: high flexibility in ramp-up and turndown process, increased cycle amount at part load at sufficient thermal efficiency $\eta_{\text {th }}$ and matching of legal requirements in terms of $\mathrm{CO}$ and NOx emissions [1], [2]. The design of the SAS providing cooling air to the combustor and turbine blades has an impact on all

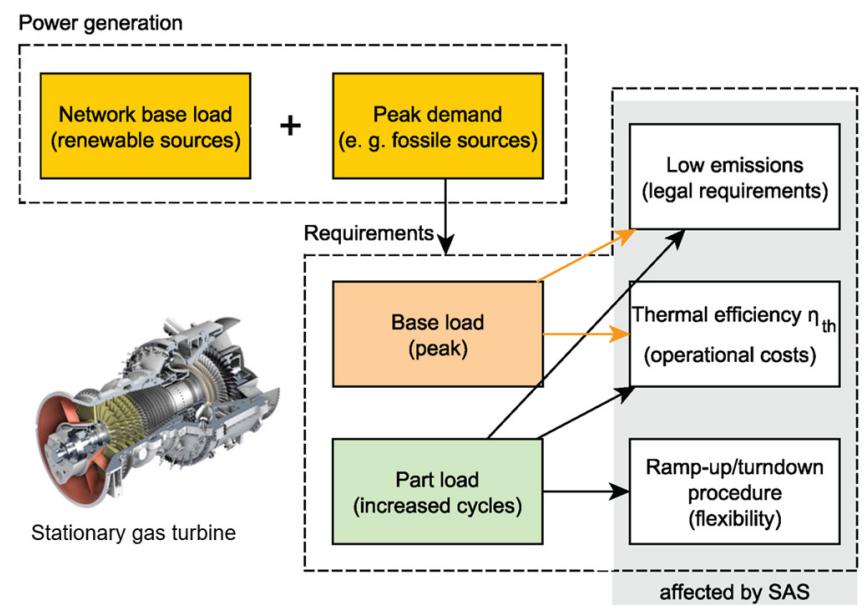

Figure 1: The SAS as key component regarding modern part load requirements 
these demands, Figure 1. Hence, the consideration of controlled cooling air circuits at part load is a key aspect of the development of future gas turbines or upgrade features. This also demands for adequate numerical methods and models for concept studies on SAS modulation at off design including the impact on whole system level.

When focusing on the SAS, turbine blade cooling and prevention of hot gas ingestion are crucial to maintain turbine integrity. Before all others, blade and vane cooling holds the highest share on overall secondary air flows wSAS with the highest portion in the first turbine stage. On the part of losses, two basic rules can be established. At first, a secondary air offtake leads to a higher penalty of $\eta_{\text {th }}$ if the bleed offtake is located in the last compressor stages or the sink is located in the rear turbine blade rows. Second, wsAs conducted through the inner, rotating SAS is typically subject to additional loss effects such as disk pumping [3].

The amount of supplied $\mathrm{W}_{\mathrm{SAS}}$ itself is a result of the pressure and temperature boundary conditions of the SAS, hence the compressor bleed offtakes and turbine sinks, and the state changes in the flow paths, mainly driven by SAS geometries and rotational speeds in the inner SAS. In other words: The SAS is closely coupled with the thermodynamic cycle. In consequence, concept studies on flexible SAS require interdisciplinary approaches such as component zooming by means of coupling a model representing the cycle with a more detailed component model - here a SAS model.

This paper's objectives are the demonstration of a methodology and a coupled model suitable for basic concept studies on controlled air supplies in the SAS, the estimation of effecting benefits regarding fuel flow consumption and addressing of recommendations for such SAS layouts. Different part load conditions are investigated besides base load at standard conditions according to [4]. Although the first turbine stage consumes the highest amount of cooling air, the studies in this paper focus on the control of secondary air supply in the second stage.

General challenges regarding SAS studies on a preliminary design level are from various kind. First of all, the final SAS layout and especially specific geometries are very individual for a gas turbine, since it is part of the result of the multidisciplinary design process. Further, geometries of original SAS equipment are barely published or just falsified, since both SAS and turbine data is typically classified by the developer. For this reason, the subsequently presented model and studies don't claim final quantifications of effects achieved by controlled Wsas. The intention is rather the publication of a coupled model for a generic stationary gas turbine, which is composed of specifications available in literature extended by state of the art assumptions, where specific data is lacking. The benchmark for this generic gas turbine is a Siemens SGT5-4000F with a four stage turbine, which has a comparable base design to an Ansaldo F-class AEx4.3A.

\section{METHODOLOGY}

The methodology applied for the coupled model to be introduced is basically derived from [5], originally demonstrated for an aero engine application. The coupled model contains three major models.

1. The performance synthesis model represents the gas turbine on a holistic level.

2. The SAS network model primarily allows for studies on changed SAS geometries at arbitrary thermodynamic boundary conditions.

3. A compact, analytical temperature evaluation model provides material temperatures $\mathrm{T}_{\text {mat }}$ in the blade rows of highest interest.

These three models are from basically different nature regarding their resolution of quantities, since they are designed for system level (performance), component level (SAS network) and part level (evaluation of $\mathrm{T}_{\text {mat }}$ ) respectively. All models are interconnected in a workflow containing additional models required for the conversion of quantities between them.

In the following subsections, the three major models are introduced regarding both their individual methodologies and the workflow for coupling. Specific model inputs of the generic gas turbine are introduced in the later section named Specific Model.

\section{Performance synthesis model}

A frequently used approach in gas turbine performance is the performance synthesis. Here, the common components of gas turbines such as intake, compressors, combustor, turbines, ducts and shafts are typically modeled as black boxes. These black boxes are usually not containing any geometrical information. Changes of quantities between inlet and outlet are resulting from the evaluation of component specific state equations. The component models are combined in a modular way to the synthesis model representing the gas turbine entirely as a network of components. In the following, the interface nodes between the components are referred to as stations. Hence, the entire model is one dimensional but typically zero dimensional on component level.

Typical inputs on system level are ambient conditions, power offtakes or power demands. On component level, flow characteristics such as compressor or turbine maps are vital, extended by certain component specific parameters, e.g. secondary air bleed offtake definitions in the compressor. In the case of the here applied model the gas turbine performance software GTlab-Performance, a code developed by the German Aerospace Centre [6], is used. The required inputs are grouped to a mandatory model input with the gas turbine's design point (DP) definition on the one side and a set with the definitions of variant cases on the other side. In the here presented paper, the latter cases are operating points (OP) at ambient temperatures and shaft power offtakes other than the nominal DP, hence off-design.

Figure 2 illustrates the synthesis model including the contained component modules. The SAS module integrated to the synthesis model is capable of considering various bleed offtake flows, which can be individually split into a limited amount of sinks. Here, most of the secondary air is returned by using discrete sinks in the turbine module. Only a small amount is transferred to void as system leakage flow. 
Performance synthesis basically doesn't know about geometries, since these are implicitly contained in component characteristics. Hence, the SAS module doesn't allow for the aimed studies and is the component to be finally zoomed in with a model of higher order.

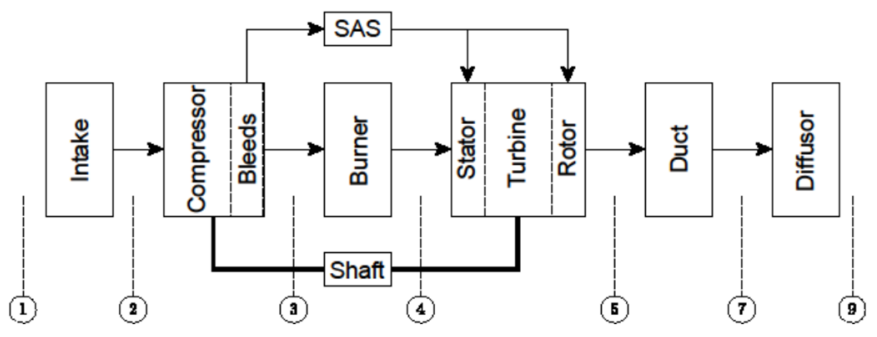

Figure 2 Performance synthesis model with components and declaration of stations

A common approach modeling cooled turbines within gas turbine performance codes is the implementation of a onestage turbine model [7], [8]. An important modeling aspect is thereby the appropriate categorization of sink flows according to the so called work split method into typically two to four sinks, Figure 3. The most essential difference between those sinks is the attribution of its flows to perform rotor work, which applies for all stations in Figure 3 b) except station 415. The turbine capacity is defined by the turbine inlet flow and sink flows from station 400. Work splits for two and three stage turbines are discussed e.g. by [7]. The here assumed relative work distribution of all four stages of the referred turbine is set to be constantly $25 \%$, motivated by the distribution given for the reference four stage turbine in [9].

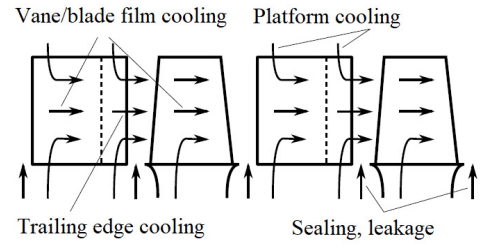

a) Real multistage turbine

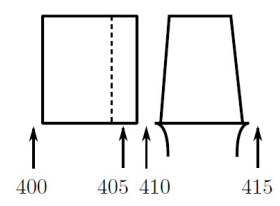

b) One stage surrogate model

\section{Figure 3 Abstraction of sink flows in one stage turbine model according to [8]}

\section{SAS network model}

The network model represents all relevant secondary air flow paths. Typical flow components are pipes, orifices, nozzles, seals or cavities. Unlike the synthesis model its inputs are usually both flow characteristics and geometries. As one dimensional model, flow characteristics are either map based including results from experiments or 3D CFD or empirical correlations.

The here applied commercial software Flownex SE (version 8.9) provides appropriate models for the most fundamental SAS elements such as pipes and labyrinth seals with a large palette for specification. SAS network modeling makes frequent use of discrete losses for the depiction of sharp edged component inlet and outlet losses, gaps and leakages. For inlet and outlet losses, the use of a loss coefficient $\mathrm{K}$ is common (Equation 1, [10]). Gaps are often modeled with the discharge coefficient $\mathrm{c}_{\mathrm{d}}$ representing the ratio of actual to ideal mass flow rate (Equation 2, [10]).

$$
K=\frac{\Delta p_{t}}{\frac{1}{2} \cdot \rho \cdot v^{2}}
$$

$w=c_{d} A \frac{p_{t, 1}}{R \cdot T_{t, 1}} \cdot \sqrt{\frac{2 \cdot \gamma}{\gamma-1} \cdot R \cdot T_{t, 1} \cdot\left[\left(\frac{p_{s, 2}}{p_{t, 1}}\right)^{\frac{2}{\gamma}}-\left(\frac{p_{s, 2}}{p_{t, 1}}\right)^{\frac{\gamma+1}{\gamma}}\right]}$

\section{Blade material temperatures}

Since the temperature field of turbine vanes and blades is very complex with large differences between hub, mean and tip radius as well as across the meridional coordinate, these conceptual studies will only deal with representative overall material temperatures. The applied model from [11] is frequently used in preliminary studies. It finally allows to correlate hot gas and coolant mass flows and temperatures with $\mathrm{T}_{\text {mat }}$ by applying a cooling coefficient $\mathrm{C}_{\mathrm{c}}$. This coefficient includes cooling efficiency $\eta_{\mathrm{c}}$, blade geometries and the Stanton number. If $\eta_{\mathrm{c}}$ can be expected to be unchanged, Cc can be taken as constant and hence be derived with the knowledge of hot gas, coolant and material parameters at a certain operating point. Equation 3 contains the form of this approach with $\mathrm{T}_{\text {mat }}$ as output. However, this approach remains only valid for conceptual studies, since $\eta_{\mathrm{c}}$ must be expected to be variable especially for film cooling.

$$
T_{\text {mat }}=\frac{\left(T_{h}+\frac{w_{c} T_{c}}{w_{h} C_{c}}\right)}{\left(1+\frac{w_{c}}{w_{h} C_{c}}\right)}
$$

\section{Workflow}

The workflow of the coupled model is based on a previously presented methodology [5]. It is implemented with an appropriate, flexible in-house code designed for gas turbine component zooming called IPSM.

The secondary air flows WAS $_{\text {SAS }}$ of the synthesis and SAS network model have to be iteratively matched. For this purpose, additional interface models are required, which are presented as well. The conversion of source and sink quantities from the synthesis to the network model is basically a zero to one dimensional transformation. Principally, guessed cooling air flows are set as input to the synthesis model. The latter delivers pressure and temperature boundary conditions to the detailed SAS network model. The network model computes from the pressure and temperature boundary conditions new values of wSAS in each flow path, which are returned in a transformed form to the synthesis model. The pressure and temperature boundary conditions are derived from interstage characteristics of compressor and turbine, which will be introduced later. A meanline approach should be preferred, if detailed component information is available. The evolution of the hot gas temperature in order to feed the evaluation of $\mathrm{T}_{\text {mat }}$ is based on an enthalpy balance of hot gas and returned sink flows as already presented in [5]. The complete workflow is depicted in Figure 4.

The basic matching has been realized with a simple iterator. However, IPSM allows switching to a couple of 
optimization algorithms which may be required at conditions, where any of the plugged simulations are not running robust.

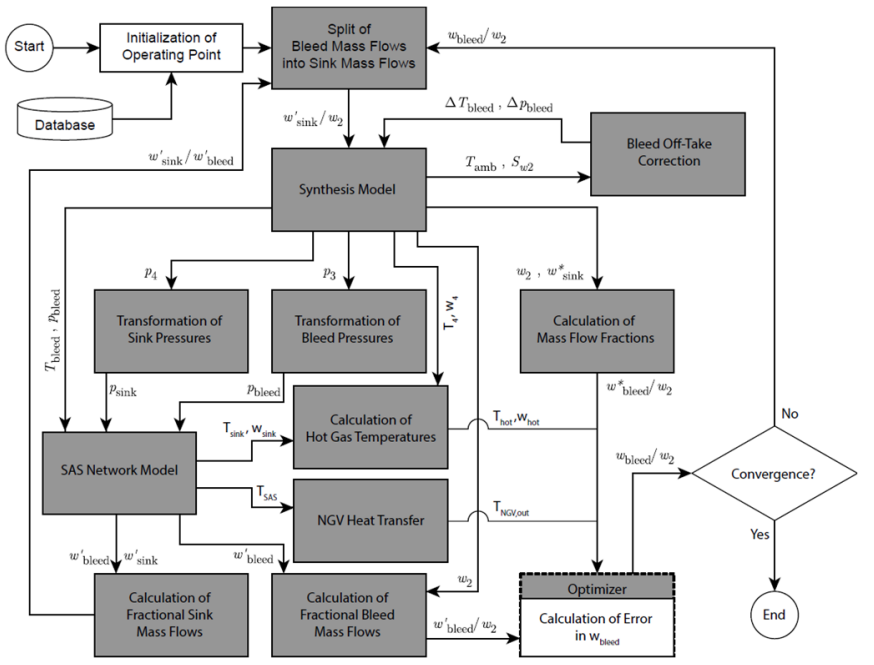

Figure 4 Applied iterative workflow for a single OP

\section{SPECIFIC MODEL}

\section{Basic gas turbine reference and operating points}

The geometry is primarily derived from an Ansaldo Fclass AEx4.3A gas turbine with a comparable base design to the SGT5-4000F. The cycle is intended to match the SGT5$4000 \mathrm{~F}$ at ISO DP conditions. Shaft speed is held constant for all operating points at $3000 \mathrm{rpm}$ according to a gearless $50 \mathrm{~Hz}$ net frequency application.

Regarding off-design: nominal and two reduced power offtake settings are investigated at three different ambient temperatures.

- $\quad \mathrm{PW}_{\mathrm{gen}}=[100,80,60] \%$

- $\mathrm{T}_{0}=[0,15,30]^{\circ} \mathrm{C}$

\section{Performance synthesis model definition}

The DP definition has been derived from several sources and checked for consistency. The final outcome is combined from [2], [12], [13]. Regarding the compressor and turbine characteristics, generic maps published in [14] have been applied. The maps are scaled to the specific DP inputs and are not required for the DP simulation itself, but necessary at offdesign. An overview of the component specific DP parameters is given in the appendix, Table 2 .

The fuel characteristic is for natural gas composed of $96 \%$ methane and $4 \%$ ethane, calibrated by the fuel heating value FHV in the DP matching scheme (Table 3).

According to [15], the power offtake at part load is controlled by application of compressor VIGVs at maintained exhaust gas temperature $\mathrm{T}_{5}$. The VIGV modeling is simplified to a compressor map mass flow scaler $S_{\mathrm{w}, \mathrm{compr}}$. The matching scheme for off-design is attached in Table 4.

The relative secondary air flows WSAS,rel are derived from air flow charts, tables and diagrams presented in [2], [12], [13]. Each individual flow's relative participation on rotor work is respected according to the already introduced work split assessed from [7], [9]. Figure 5 schemes the SAS circuits including the subsequently applied offtake and sink naming convention, the relative amounts of flows related to the compressor inlet mass flow in percentage and the relative rotor work contribution. It has to be noted, that circuit E1o as sealing air supply for stage four was not modeled in the final SAS network, but of course considered within the synthesis model.

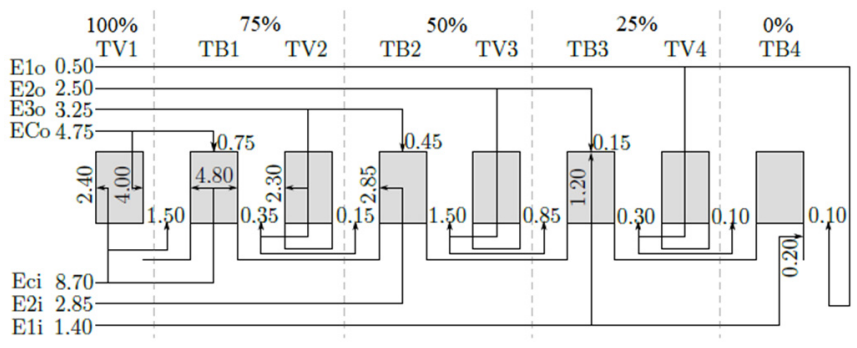

Figure 5 Relative sink mass flows and rotor work

\section{SAS network model definition}

The geometry of the SAS network model has been derived from various drawings of the Ansaldo F-class AEx4.3A turbine published in [2], [16], [17], scaled to the overall Siemens SGT5-4000F layout originally accessed in [18]. All depicted SAS flow elements have been measured with a graph data extraction tool. This approach shows measurement uncertainties mainly resulting from the referred graphs resolutions itself. A quantification of the derived dimensions accuracy can be exemplary given for the turbine disk stage two cooling bore, fed from a rotating interstage cavity and providing cooling air to the blade root. The uncertainties for the bore diameter $\mathrm{d}$ and length 1 are given in Table 1 with absolute values and relative uncertainties referred to the measured, nominal values.

Table 1 Measure uncertainty for stage two disk cooling bore

\begin{tabular}{llll} 
& lower & nominal & upper \\
\hline $\mathrm{d}[\mathrm{mm}]$ & 17.46 & 22.76 & 24.38 \\
rel. deviation [\%] & -15.8 & & 17.4 \\
$1[\mathrm{~mm}]$ & 203.27 & 209.5 & 215.79 \\
rel. deviation [\%] & -3.0 & & 3.0
\end{tabular}

The resulting SAS geometry does not match the expected flow amounts in the individual circuits instantly. This is both the result of uncertainties and general neglects in modeling. For example, not all flows can be derived from open literature. This is especially true for several inter-SAS leakage flows. With the objective of matching the SAS geometry at DP pressure boundary conditions to the expected relative flows in Figure 5, a matching procedure has been conducted. The degrees of freedom are key geometries like diameters within the tolerances resulting from Table 1 as well as additional parameters as commented subsequently.

The following list contains all important element types with their component types in Flownex SE chosen to be 
suitable for simulation. It also includes specific empirical quantities taken from literature.

- $\quad$ Static pipes: Common pipe element extended with a secondary loss element at each inlet and outlet. The inlet loss has been selected to $\mathrm{K}=0.6$ and the outlet loss to $\mathrm{K}=1.0$, according to the empirical suggestions in [19].

- Rotating pipes and channels, independent of primarily axial or radial extent: Rotating channel element with directly defined inlet loss $\mathrm{K}=0.6$ and outlet loss $\mathrm{K}=1.0$.

- Cavities from primarily axial extent: Rotating annular gap element.

- Cavities from primarily radial extent: Rotor-stator cavity element for consideration of swirl and swirl pressure evolution. This component allows the consideration of multiple arms at different radii.

- Labyrinth seals: Use of the labyrinth seal component as straight seal (ECi rim seal supply) and staggered seal (E2o and E3o vanes downstream rim seal supplies). The number of fins was derived from the published drawings in [16]. Running clearances $\delta_{\text {seal }}$ cannot be derived sufficiently from drawings and were degrees of freedom within the DP flow matching procedure, all kept in the range $\delta_{\text {seal }}=\mathrm{c}_{\delta} \cdot \mathrm{r}_{\text {seal }}$ with $\mathrm{c}_{\delta}=[0.0016 ; 0.0076]$ [20].

- Blade cooling characteristics: User specified pressure ratio components were applied with curves from type $\mathrm{w}_{\mathrm{red}}=\mathrm{f}\left(\mathrm{p}_{\text {sink }} / \mathrm{p}_{\mathrm{t}, \text { in }}\right)$ with "in" as component's inlet. The curves have been individually fit to the stage one blade characteristic depicted in [2]. Scaling factors on $\mathrm{w}_{\text {red }}$ have been used as major degrees of freedom in the DP flow matching procedure. Due to the lack of additional, individual characteristics all cooled blades and vanes are modeled using that generalization. This was accepted even though it has a major effect on the quality of off-design studies.

- Rim seals: No special features are implemented in the reference turbine such as interlocking plates common in aero engine applications or labyrinth seals. For the stream merging, a discharge coefficient of $\mathrm{c}_{\mathrm{d}}=0.8$ is assumed.

- Control valves: The butterfly valve component has been chosen for control valves in circuits E2o and E3o. Unfortunately, no dimensions are available in the referenced literature regarding the entire supply paths from the compressor to the static cavities in the turbine casing. Hence, the related diameters were defined generously to guarantee no flow restrictions triggered by this part of the SAS.

- Vane heat transfer: The hub region supply flows transferred through the vanes of stage two and three require attribution of heating by the annulus flow. For the here presented studies, the temperature at vane hub outlet is assumed to be increased by $\Delta \mathrm{T}_{\mathrm{SAS}}=100 \mathrm{~K}$ in vane two and $\Delta \mathrm{T}_{\mathrm{SAS}}=50 \mathrm{~K}$ in vane three. The coolant temperatures $\mathrm{T}_{\mathrm{c}}$ applied in equation 3 are not these heated temperatures, but the vanes inlet temperatures.

The entire network as implemented in Flownex SE is depicted in the appendix, Figure 15.

Regarding the DP matching procedure, the rim seal flows branched from the stage two vane transfer supply can't be sufficiently matched with the introduced clearance factor $\mathrm{c}_{\delta}$. The target mass flow ratio between rim seal upstream of vane two, subsequently named TV2hub, and downstream, subsequently named TB2hub, of $(2.4 / 1.03)$ is mismatched with $(1.9 / 1.64)$. These two sink flows can't be sufficiently arranged in the network model without violating the assumptions made before. The target flow ratio would be achieved by a clearance of approximately $65 \%$ to the defined lower bound, which has been rejected for this model, hence basically tolerating the unmatched flows.

\section{Transformation of SAS boundary conditions}

The transformation of static bleed pressures is based on the compressor interstage characteristic presented in [2], which also includes a correction for cold and warm day conditions. For bleed temperatures, a compressor interstage characteristic has been generated, derived from the assumption of a constant stage enthalpy $\Delta \mathrm{h}_{\mathrm{t}, \mathrm{st}}$ over the compressor.

The turbine sink pressures at mean radius are calculated at runtime from the turbine interstage characteristic presented in [2]. This characteristic is the base for the subsequently described corrections, too. Static rim pressures downstream of vanes are derived from a radial pressure distribution of the stage one vane outlet referred in [9]. Leakages and wall cooling flows from the outer, static SAS above blade tips are derived by applying the radial pressure distribution in the relative system of rotor blade stage four outlet in [9]. Rim seal pressures downstream of the blades were in first order approximated to be equal to the before mentioned tip pressures. Absolute DP pressure quantities are attached to the appendix, Table 5.

\section{Transformation of SAS flows}

The sink mass flows resulting from the SAS network model simulation are divided into the shares performing rotor work and no work. Depending on their relative rotor work contribution as defined in Figure 5 they are assigned to one of the sinks in the performance model's turbine module as depicted in Figure 3. For example, the blade cooling flow of the rotor blade stage three, supplied in circuit E1i, is returned to a share of $25 \%$ to station 410 . The rest is returned to station 415. The bleed flows defined in the compressor module are summed from the associated sink flows.

\section{Blade material temperatures}

The representative vane and blade material temperatures are directly taken from [13] and assumed to be valid at the here defined DP. Hence, the cooling coefficient $\mathrm{C}_{\mathrm{c}}$ in Equation 3 is calibrated onto these temperatures. 


\section{STUDIES}

The model holds uncertainties regarding geometry and boundary conditions since not all information is available. In order to assess the effect of these uncertainties two sensitivity studies are performed: The first focuses on model geometries by varying selected geometrical parameters. The second investigates trends of cooling and rim mass flows varying sink pressures. This gives both an insight into the influence of mismatched pressure assumptions especially at hub sink pressures and an understanding of the stability of the individual flow paths design in regard to possible flow reversal. Since this model is intended to represent a nominal SAS design, these studies discuss the basic model responses to geometry and pressure changes. These studies do not reflect specific production uncertainties. The third set of studies deals with a comparison of the uncontrolled and controlled cooling circuit E3o at off-design. Although stage one consumes more cooling air, this approach was chosen for demonstration purposes, as it does not involve significant design changes. Here, the baseline of $\mathrm{T}_{\mathrm{mat}, \mathrm{DP}}$ from the studies at uncontrolled circuits is defined as target for the controlled operation. Hence, the minimization of previously derived margins $\Delta \mathrm{T}_{\text {mat }}$ is the objective.

\section{Impact of uncertainties in geometry of SAS network model}

The following sets of geometry variations have been investigated on the SAS network model after the DP matching procedure. The parameters are altered $\pm[1,2.5,5] \%$ to their base quantities. This variation has been chosen to demonstrate the basic impacts of geometry variation to the associated sink flows in order to identify the main flow restrictors.

- Seal tip clearances $\delta_{\text {seal: }}$ The impacts on rim seal flows are depicted for the seal in circuit ECi (TB1hub) and E3o (TV2hub, TB2hub), Figure 6. For the relative clearance $\delta_{\text {seal,ECi,rel }}=105 \%$ the rim flow TB1hub increases to a relative amount of $131 \%$ of the base configuration. This mass flow is therefore very sensitive to enlarged sealing gaps. The seal in circuit E2i was investigated as well, but showed no significant changes in rim flows at the applied relative variations.

- $\quad c_{d}$ in rim seals mixing planes to the annulus: For all flow paths in TV2rim, TB2rim, TV3rim, TB3rim no relevant impact could be detected. Thus, the hub region design is not regarded to be flow restricting.

- Areas $A_{\text {drill: }}$ The supply flows transferred through the vanes, here named TV2transfer and TV3transfer, are finally impinged onto the hub area through drills. Downstream, the flow is branched to the associated TVhub (vane upstream) and TBhub (vane downstream) paths. The drill cross sectional area has apparent impact on the flows TVhub, as depicted in Figure 7. However, the flows in TBhub (not contained in Figure 7) are more or less unaffected. This is suspected to be a result of the labyrinth seals between the node downstream of the drillings and TBhub sinks, acting as flow restrictors, but venting the TVtransfer flows to the relative low static pressure downstream the vane. The restriction by the drillings itself hence seems to be primarily adjusting TVhub flows. Consequently, they are an important degree of freedom in the model calibration.

- $\quad \mathrm{c}_{\mathrm{d}}$ in case sided tip leakage flows: The manipulation of leakage areas by altering $c_{d}$ can be stated to have a direct linear proportional effect on the sink flows within the investigated range, Figure 8.

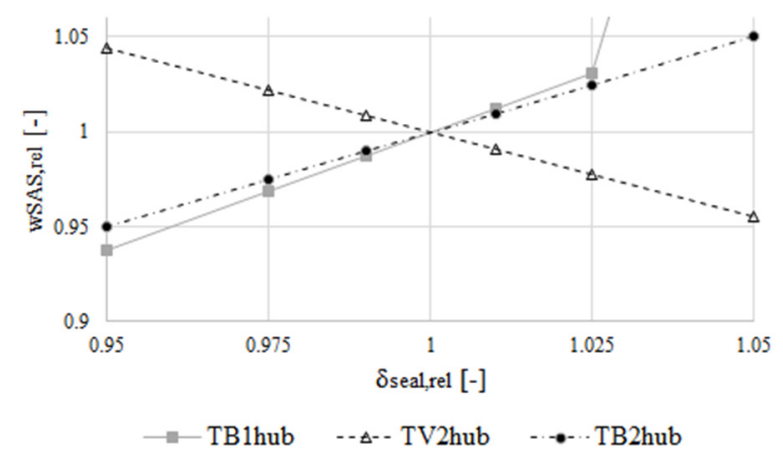

Figure 6 Sensitivities in rim seal flows regarding seal clearances

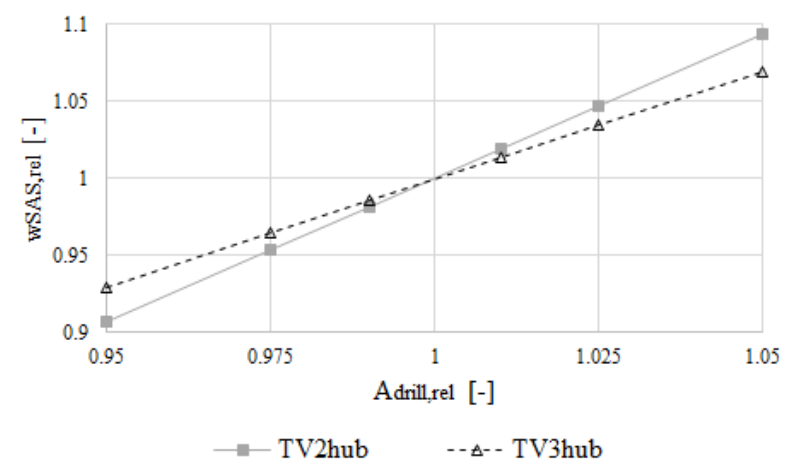

Figure 7 Sensitivities in rim seal flows regarding drillings in vane transfer flows

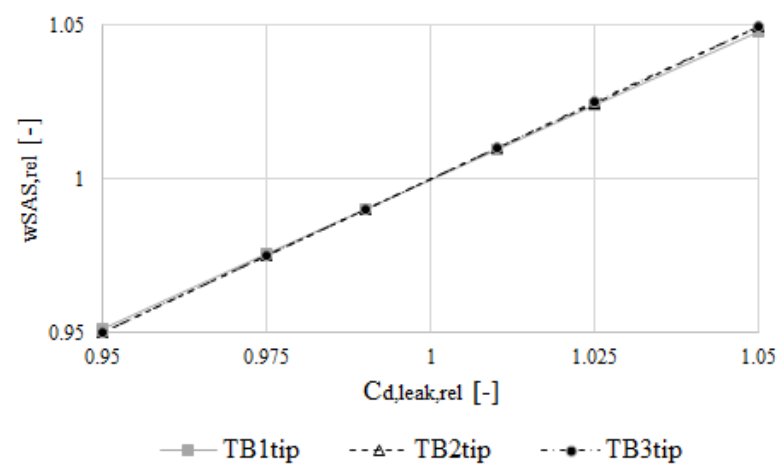

Figure 8 Sensitivities in tip leakage flows regarding gap areas

Impact of uncertainties in pressure distribution of SAS network model

The influence of sink pressure is individually investigated for following sinks: The stage two vane cooling TV2 and both 
TVhub and TBhub flows of stages two and three. Relative to the introduced DP pressure settings, six exemplary modifications are included at $\pm[1,2.5,5] \%$. As with the geometry variation, this distribution is selected for the general evaluation of the sensitivities.

Figure 9 sketches the sensitivities of the sink flows around stage two vane. It is shown, that there is a relatively moderate, almost linear effect on the vane film cooling itself and the two downstream rim flows. The upstream rim flow TV2hub is significantly affected by the pressure variation. This implies that an accurate pressure definition is essential regarding investigations of this flow. At the same time, the upstream rim flow is per se sensitive compared to TB2hub, since both sink flows share the same supply flow: The static pressure drop across the vane favors venting towards the downstream sink at a lower pressure level.

Figure 10 shows the same trend for TV3hub and TB3hub as discussed for stage two. However, the sensitivity of the TV3hub flow on its sink pressure is weaker than observed in TV2hub. This is obviously explained by the absence of film cooling in that stage.

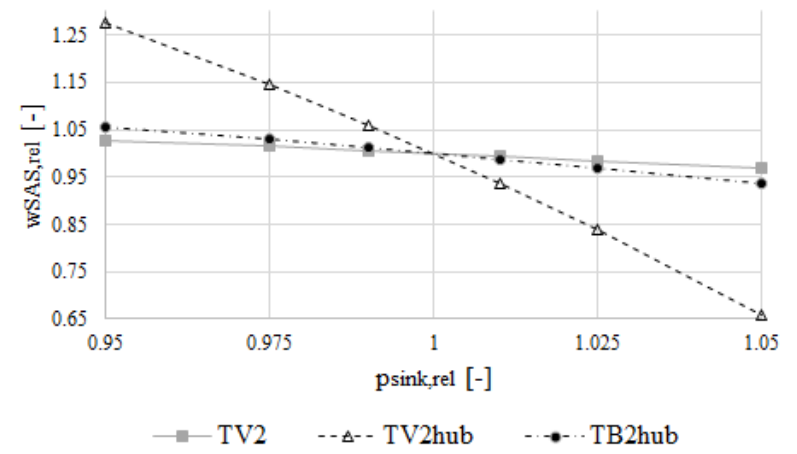

Figure 9 Sensitivities in sink flows across stage two vane regarding pressure levels

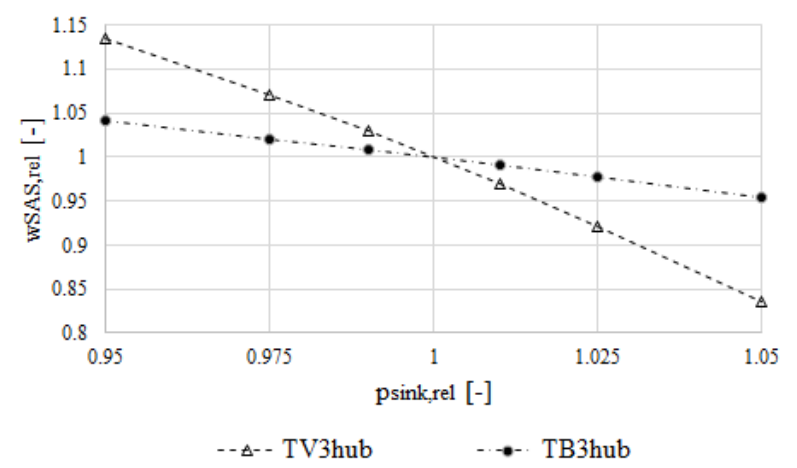

Figure 10 Sensitivities in sink flows across stage three vane regarding pressure levels

\section{Comparison of part load operation at uncontrolled} and controlled cooling circuit E3o

This series considers gas turbine operation at both uncontrolled and controlled vane cooling in stage two. The circuit control of E3o is achieved by throttling the integrated butterfly valve. Subsequently, all margins $\Delta \mathrm{T}_{\text {mat }}$ at uncontrolled operation are related to the DP condition, hence $\mathrm{PW}_{\text {gen,rel }}=100 \%$ and $\mathrm{T}_{0}=15^{\circ} \mathrm{C}$. A negative value of $\Delta \mathrm{T}_{\text {mat }}$ signalizes the vane temperature to be lower than the reference of $\mathrm{T}_{\text {mat, } \mathrm{TV} 2}=1094 \mathrm{~K}$ from [13], hence representing a condition suitable for cooling air reduction. Thus, this vane two baseline material temperature is set as target for control in E3o at part load.

Figure 11 depicts remaining $\Delta \mathrm{T}_{\text {mat }}$ for three sets at different power output settings and ambient conditions. Since the DP itself is not subject to cooling air optimization $\left(\Delta \mathrm{T}_{\text {mat }}=0 \mathrm{~K}\right.$ by default $)$, it is left out. The set named "reference" represents uncontrolled operation. As expected, vane temperatures are decreasing with lower power outputs and ambient temperatures. The warm day is not suitable for cooling air reduction, since $T_{\text {mat }}$ is above $T_{\text {mat,DP. }}$.

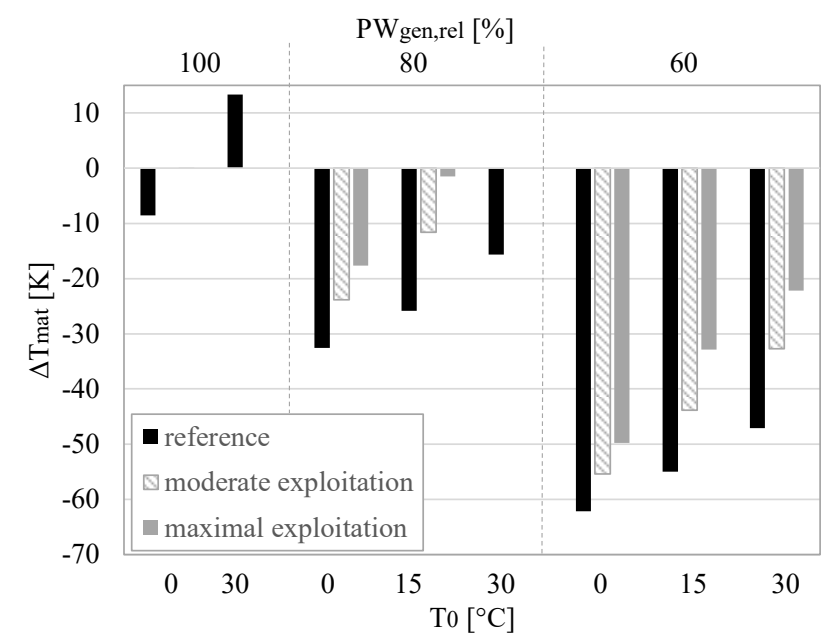

Figure 11 Margins in $\mathrm{T}_{\text {mat }}$ at both uncontrolled and controlled secondary air supply

The objective of reducing $\Delta \mathrm{T}_{\text {mat }}$ to zero is only achieved for the cold day at $\mathrm{PW}_{\text {gen,rel }}=100 \%$ and the warm day at $\mathrm{PW}_{\text {gen,rel }}=80 \%$ (no bars visible). In other OPs, the cooling air reduction is limited by hot gas ingestion in the sink TV2hub:

- The valve throttling results in a changed pressure distribution at the cost of decreased pressure margin especially in TV2hub, also comparable to the findings in Figure 9.

- The applied compressor interstage characteristic provides relatively low offtake pressures at cold day conditions. This is why $\Delta \mathrm{T}_{\text {mat }}$ is better exploited at warm day conditions, even if the reference margins are significantly higher at cold days.

In the simulations of set "maximal exploitation", the net flow in TV2hub was allowed to approach zero. Unfortunately, local hot gas ingestion is initially independent of the net flow itself. Hence, these maximal exploitations must be assumed to come along with severe hot gas ingestion. The set named "moderate exploitation" suggests a net flow half to WTV2hub at uncontrolled operation as alternative limiter. This completes Figure 11 to a generic trend of $\mathrm{T}_{\text {mat }}$ exploitation with hot gas prevention as constraint. It has to be noted, that the moderate exploitation is not depicted for the before mentioned OPs $\left(\mathrm{PW}_{\text {gen,rel }}=100 \%, \mathrm{~T}_{0}=0^{\circ} \mathrm{C}\right)$ and $\left(\mathrm{PW}_{\text {gen,rel }}=80 \%, \mathrm{~T}_{0}=30^{\circ} \mathrm{C}\right)$, 
since this alternative criterion is not reached by the full exploitation of $\Delta \mathrm{T}_{\text {mat }}$. The associated cooling mass flows referred to uncontrolled operation are attached in the appendix, Figure 14.

Figure 12 shows the resulting fuel flow savings expressed as $\Delta \mathrm{w}_{\text {fuel }}$, each related to its respective OP with uncontrolled secondary air supply. The outcome from this specific model is a noticeable benefit of air modulation at reduced power offtakes, if severe local hot gas ingestion is prevented.

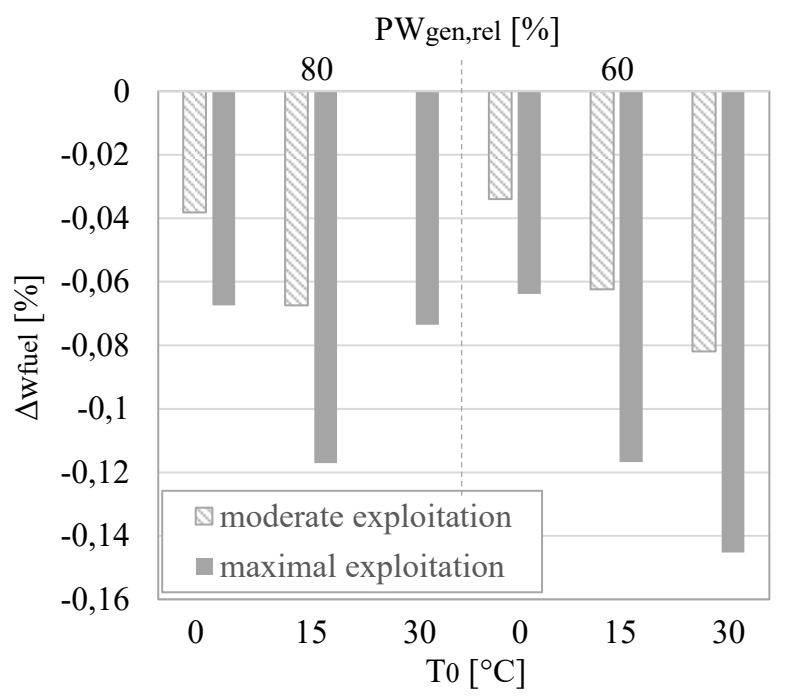

Figure 12 Fuel flow benefits resulting for controlled secondary air supply

E3o circuit as alternative rotor blade cooling supply

Another version of the presented model was applied to a case study using the TV2transfer flow as alternative cooling air supply of blade stage two. The motivation for this study was the reduction of parasitic losses caused in the rotating part of the SAS. Additionally, this concept would directly provide the possibility of TB2 cooling air control by the E3o valve. For this purpose, the hub region of vane two was extended by another flow, directly supplying air to the hub cavity downstream of the vane. The impingement was realized by a pre-swirl nozzle integrated to the model. The original supply circuit E2i was totally removed and the disk cooling bore was rearranged to be fed from the rim seal cavity beneath TB2hub. This concept is sketched in Figure 13.

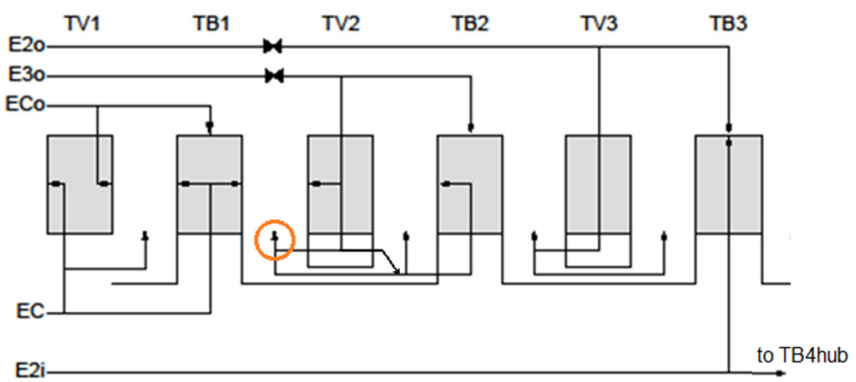

Figure 13 SAS configuration of alternative blade stage two cooling supply

The preliminary outcome of this study is that the discussed problematic sink TV2hub (highlighted in Figure 13) is even harder affected than at the base design. This is caused by TB2 as another sink downstream at relatively low pressure. Consequently, such concepts must be expected to be highly sensitive to hot gas ingestion. Besides that the final conceptual realization of this concepts cannot be discussed within the scope of the undertaken conceptual studies.

\section{CONCLUSIONS}

A modeling approach with a literature based, specific coupled model of a generic stationary gas turbine has been introduced. This model has been applied to a set of parameter studies regarding its sensitivities to geometrical input and pressure boundaries. On the one hand the necessity of detailed original model input data has been pointed out in order to verify quantitative results. According to [5], the consideration of all leakage flows is beneficial regarding the overall model accuracy as well. On the other hand the application of this model was demonstrated to be suitable for academic purpose, allowing the investigation of trends in conceptual studies. Such may both include general design changes and secondary air control in arbitrary flow paths. At the same time, the model serves as template for stationary gas turbines with similar base design.

Based on this model, general trends for secondary air circuit control at part load have been demonstrated. The most important findings are recapitulated subsequently:

- Cooling air reduction can be beneficial regarding operational costs. At ISO day conditions, the fuel flow savings for power outputs to $80 \%$ or $60 \%$ is at approximately $\mathrm{w}_{\text {fuel }}=0.12 \%$ for a theoretical full exploitation of $\mathrm{T}_{\text {mat }}$ and still at $\Delta \mathrm{w}_{\text {fuel }}=0.06 \%$ for a moderate exploitation. These benefits are for E3o valve control only and under the assumption that blade creep life consumption at part load is accepted to be as high as during base load operation.

- The consideration of changed sealing flows for hot gas prevention is mandatory, when they are arranged in a controlled circuit. Distinct criteria or ingestion models have to be set as limiters for cooling air reduction.

- Surprisingly, for this model warm day operation benefits more on cooling air control than cold day operation.

The findings regarding rim flow sensitivities also demand for advanced sealing concepts in stationary gas turbines. Appropriate enhancements are most obviously beneficial for the overall efficiency apart from SAS control.

\section{NOMENCLATURE}

Symbols

$\begin{array}{ll}0 & \text { Ambient conditions } \\ 1 & \text { Inlet station } \\ 2 & \text { Compressor inlet station } \\ 4 & \text { Turbine inlet station } \\ 5 & \text { Turbine outlet station } \\ \beta & \text { Auxiliary parameter in turbo component } \\ \gamma & \text { maps } \\ & \text { Ratio of specific heats }\end{array}$




\begin{tabular}{|c|c|}
\hline$\Delta$ & Difference \\
\hline$\delta$ & Clearance \\
\hline$\eta$ & Efficiency \\
\hline$\Pi$ & Pressure ratio \\
\hline$\rho$ & Density \\
\hline $\mathrm{A}$ & Area \\
\hline $\mathrm{C}$ & Coefficient \\
\hline $\mathrm{d}$ & Diameter \\
\hline $\mathrm{h}$ & Specific enthalpy \\
\hline 1 & Length \\
\hline $\mathrm{N}$ & Shaft speed \\
\hline $\mathrm{p}$ & Pressure \\
\hline $\mathrm{Pw}$ & Power \\
\hline $\mathrm{R}$ & Specific gas constant \\
\hline S & Scaling factor \\
\hline $\mathrm{T}$ & Temperature \\
\hline $\mathrm{v}$ & Velocity \\
\hline w & Mass flow \\
\hline \multicolumn{2}{|l|}{ Indices } \\
\hline $\mathrm{c}$ & Coolant \\
\hline compr & Compressor \\
\hline d & Discharge \\
\hline drill & Supply drilling \\
\hline fuel & Fuel \\
\hline gen & Generator \\
\hline $\mathrm{h}$ & Hot gas \\
\hline leak & Leakage \\
\hline mat & Material \\
\hline red & Reduced \\
\hline rel & Relative \\
\hline $\mathrm{s}$ & Static quantity \\
\hline seal & Labyrinth seal \\
\hline shaft & Shaft \\
\hline $\operatorname{sink}$ & Sink flow \\
\hline st & Stage \\
\hline $\mathrm{t}$ & Total quantity \\
\hline th & Thermal \\
\hline turb & Turbine \\
\hline \multicolumn{2}{|c|}{ Abbreviations } \\
\hline DP & Design point \\
\hline E2o & $\begin{array}{l}\text { Secondary air circuit, primarily providing } \\
\text { vane stage three cooling and rim seal air }\end{array}$ \\
\hline E3o & $\begin{array}{l}\text { Secondary air circuit, primarily providing } \\
\text { vane stage two cooling and rim seal air }\end{array}$ \\
\hline FAR & Fuel to air ratio \\
\hline FHV & Fuel heating value \\
\hline IPSM & $\begin{array}{l}\text { Interface for performance and secondary air } \\
\text { system modeling }\end{array}$ \\
\hline ISO & $\begin{array}{l}\text { International organization for } \\
\text { standardization }\end{array}$ \\
\hline OP & Operating point \\
\hline SAS & Secondary air system \\
\hline TB1 & Blade stage one \\
\hline TB2 & Blade stage two \\
\hline TB3 & Blade stage three \\
\hline TBhub & Rim sink upstream of associated blade \\
\hline TV1 & Vane stage one \\
\hline TV2 & Vane stage two \\
\hline
\end{tabular}

$\begin{array}{ll}\text { TV3 } & \text { Vane stage three } \\ \text { TVhub } & \text { Rim sink upstream of associated vane } \\ \text { TVtransfer } & \text { Rim seal supply transferred through vane }\end{array}$

ACKNOWLEDGEMENTS

The major part of the presented research was funded by Siemens AG. The authors acknowledge in particular Dr. Kunyuan Zhou for his support in this project.

Additionally, we thank the German Aerospace Centre as chair's partner providing the performance code GTlabPerformance. The final studies were conducted using the software Flownex SE. The authors acknowledge CFX Berlin Software $\mathrm{GmbH}$ and M-Tech Industrial, LLC for the provision of test licenses.

\section{REFERENCES}

[1] Nag, P. et al. (2010). Low Load Operational Flexibility for Siemens F- \& G-Class Gas Turbines. Proceedings of ASME Turbo Expo 2010, Glasgow, United Kingdom, GT2010-22055.

[2] Bozzi, L., D'angelo, E. (2012). Numerical and Experimental Investigation of Secondary Flows and Influence of Air System Design on Heavy-Duty Gas Turbine Performance. Proceedings of ASME Turbo Expo 2012, Copenhagen, Denmark, GT2012-68392.

[3] Zeller, P. (2008). Effizienzsteigerung von Turboluftstrahltriebwerken durch Optimierung des sekundären Luftsystems. Dissertation, University of Stuttgart, Stuttgart, Germany.

[4] ISO 2314 (2009). Gas turbines - Acceptance tests. ISO 2314:2009(E). Geneva, Switzerland.

[5] Woelki, D., Peitsch, D. (2016). Betriebspunktabhängige Kühlluftführung für Gasturbinen. Final report to project $A G$ Turbo 2020 3.1.4, FKZ 03ET2013P, doi:10.2314/GBV:874374596.

[6] Becker, R.G. et al. (2011). Development of a gas turbine performance code and its application to preliminary engine design. 60th German Aerospace Congress (DLRK), Bremen, Germany.

[7] Kurzke, J. (2002). Performance Modeling Methodology: Efficiency Definitions for Cooled Single and Multistage Turbines. Proceedings of ASME Turbo Expo 2002, Amsterdam, Netherlands, GT2002-30497.

[8] Walsh, P.P., Fletcher, P. (2004). Gas Turbine Performance. Blackwell Science Ltd, Oxford, United Kingdom.

[9] Becker, R. (2001). Auslegung und deterministische Optimierung stark gekühlter Turbinen. Dissertation, Technical University of Munich, Munich, Germany.

[10] Brillert et al. (1999). Calculation of Flow Losses in Rotating Passages of Gas Turbine Cooling Systems. Proceedings of ASME Turbo Expo 2010, Indianapolis, USA, GT2012-68392.

[11] Louis, J.F. et al. (1983). A Comparative Study of the Influence of Different Means of Turbine Cooling on Gas Turbine Performance. Proceedings of ASME 1983 International Gas Turbine Conference and Exhibit, Phoenix, USA, 83-GT-180. 
[12] Cerri, G., Chennaoui, L. (2013). General Method for the Development of Gas Turbine Based Plant Simulators: An IGCC Application. Proceedings of ASME Turbo Expo 2013, San Antonio, USA, GT2013-94040.

[13] Cerri, G. et al. (2014). Expander Models for a Generic 300 MW F Class Gas Turbine for IGCC. Proceedings of ASME Turbo Expo 2014, Düsseldorf, Germany, GT2014-26493.

[14] Kurzke, J. (2004). Component Map Collection 2 Compressor and Turbine Maps for Gas Turbine Performance Computer Programs. Joachim Kurzke, Dachau.

[15] Lechner, C., Seume, J. (2010). Stationäre Gasturbinen. Springer Verlag, Berlin, Germany.

[16] Bonzani, F. et al. (2010). 1D Tool for Stator-Rotor Cavities Integrated into a Fluid Network Solver of Heavy-Duty Gas Turbine Secondary Air System. Proceedings of ASME Turbo Expo 2010, Glasgow, United Kingdom, GT2010-22203.

[17] Bozzi, L. et al. (2012). Procedure for Calculation of Component Thermal Loads for Running Clearances of Heavy-Duty Gas Turbines. Proceedings of ASME Turbo Expo 2012, Copenhagen, Denmark, GT201268184.

[18] Siemens AG (2010). Compressor Mass Flow Increase Upgrade for SGT5-4000F [online]. http://www.energy.siemens.com/us/pool/hq/services/ powergeneration/product-related-services/sgt54000f-v94-3a/Mass-flow\%205-4000.pdf, fetched: December, 12th, 2015.

[19] Idel'chik, I.E. (1960). Handbook of hydraulic resistance. Coefficients of Local Resistance and of Friction. $3^{\text {rd }}$ ed. The U.S. Atomic Energy Commision, Washingtion, USA.

[20] Aslan-zada, F.E. et al. (2012). Brush seals and labyrinth seals in gas turbine applications. Journal of Power and Energy, 227(2) 216-230, doi: $10.1177 / 0957650912464922$.

\section{APPENDIX}

Table 2: Performance model design point definition

\begin{tabular}{lll} 
Parameter & Symbol & Value \\
\hline Ambient static pressure & $\mathrm{p}_{\mathrm{amb}}$ & $101325 \mathrm{~Pa}$ \\
Ambient static temperature & $\mathrm{T}_{\mathrm{amb}}$ & $288.15 \mathrm{~K}$ \\
Relative humidity & $\mathrm{RH}$ & 0.6 \\
Inlet mass flow & $\mathrm{w}_{0}$ & $685.4 \mathrm{~kg} / \mathrm{s}$ \\
Inlet pressure loss & $\mathrm{p}_{\mathrm{t} 2} / \mathrm{p}_{\mathrm{t} 1}$ & 0.996 \\
Compressor pressure ratio & $\Pi_{\mathrm{C}}$ & 18.2 \\
Compressor isentropic & $\eta_{\mathrm{C}, \text { is }}$ & 0.923 \\
efficiency & & \\
Relative compressor leakage & $\mathrm{w}_{\text {leak }} / \mathrm{w}_{2}$ & 0.0075 \\
Lower heat value & $\mathrm{H}_{\mathrm{u}}$ & $50.06 \mathrm{MJ} / \mathrm{kg}$ \\
Combustor fuel flow & $\mathrm{w}_{\text {fuel }}$ & $15.0 \mathrm{~kg} / \mathrm{s}$ \\
Combustor pressure ratio & $\Pi_{\mathrm{B}}$ & 0.97 \\
Combustion efficiency & $\eta_{\mathrm{B}}$ & 0.995 \\
Turbine entry temperature & $\mathrm{T}_{\mathrm{t} 4}$ & $1713.15 \mathrm{~K}$ \\
Turbine isentropic efficiency & $\eta_{\mathrm{T}, \text { is }}$ & 0.8951 \\
Exhaust pressure ratio & $\mathrm{p}_{\mathrm{t} 5} / \mathrm{p}_{\mathrm{t} 4}$ & 1
\end{tabular}

Shaft speed

Mechanical efficiency

Generator power
N

$\eta_{\text {mech }}$

$\mathrm{PW}_{\text {gen }}$

$3000 \mathrm{rpm}$

0.995

299.6 MW

\section{Table 3 Performance model matching scheme for DP model calibration}

\begin{tabular}{lll}
\multicolumn{1}{c}{ Independent } & \multicolumn{2}{c}{ Dependent } \\
\multicolumn{1}{c}{ Parameter } & \multicolumn{1}{c}{ Parameter } & \multicolumn{1}{c}{ Target value } \\
\hline FHV & $\mathrm{T}_{\mathrm{t} 4}$ & $1713.5 \mathrm{~K}$ \\
FAR $_{\text {burner }}$ & $\mathrm{W}_{\text {fuel }}$ & $15.0 \mathrm{~kg} / \mathrm{s}$ \\
PW $_{\text {gen }}$ & $\mathrm{PW}_{\text {gen }}$ & $299.6 \mathrm{MW}$
\end{tabular}

Table 4 Performance model matching scheme for off-design

\begin{tabular}{|c|c|c|}
\hline \multirow{2}{*}{$\begin{array}{c}\text { Independent } \\
\text { Parameter }\end{array}$} & \multicolumn{2}{|c|}{ Dependent } \\
\hline & Parameter & Target value \\
\hline $\mathrm{w}_{1}$ & $\Delta \mathrm{w}_{2}$ & $0.0 \mathrm{~kg} / \mathrm{s}$ \\
\hline$\beta_{\text {compr }}$ & $\Delta \mathrm{w}_{4}$ & $0.0 \mathrm{~kg} / \mathrm{s}$ \\
\hline FAR & $\Delta \mathrm{PW}_{\text {shaft }}$ & $0.0 \mathrm{~W}$ \\
\hline$\beta_{\text {turb }}$ & $\Delta \mathrm{p}_{9}$ & $0.0 \mathrm{~Pa}$ \\
\hline $\mathrm{S}_{\mathrm{w}, \mathrm{compr}}$ & $T_{t 5}$ & $849.94 \mathrm{~K}$ \\
\hline
\end{tabular}

Table 5: Definition of target SAS flow distribution

\begin{tabular}{llrr} 
Sink & Source & W $_{S A S, D P}[\mathrm{~kg} / \mathrm{s}]$ & $\mathrm{p}_{\text {sink, DP }}[\mathrm{Pa}]$ \\
\hline $\mathrm{TV} 1_{\text {te }}$ & ECi & 16.45 & 1515312.4 \\
$\mathrm{TV} 1_{\text {le }}$ & ECo & 27.42 & 1515312.4 \\
$\mathrm{~TB} 1_{\text {hub }}$ & ECi & 10.28 & 1410479.4 \\
$\mathrm{~TB} 1_{\text {blade }}$ & ECi & 32.9 & 1157147.6 \\
$\mathrm{~TB} 1_{\text {tip }}$ & ECo & 5.14 & 1102632.3 \\
$\mathrm{TV} 2_{\text {hub }}$ & E3o & 2.4 & 1102632.3 \\
$\mathrm{TV} 2_{\text {le }}$ & E3o & 15.76 & 872452.6 \\
$\mathrm{~TB} 2_{\text {hub }}$ & E3o & 1.03 & 812094.2 \\
$\mathrm{~TB} 2_{\text {le }}$ & E2i & 19.53 & 642859.8 \\
$\mathrm{~TB} 2_{\text {tip }}$ & E3o & 3.08 & 612573.5 \\
$\mathrm{TV} 3_{\text {hub }}$ & E2o & 10.28 & 612573.5 \\
$\mathrm{~TB} 3_{\text {hub }}$ & E2o & 5.83 & 418869.7 \\
$\mathrm{~TB} 3_{\text {conv }}$ & E1i & 8.22 & 321429.9 \\
$\mathrm{~TB} 3_{\text {tip }}$ & E2o & 1.03 & 321429.9
\end{tabular}

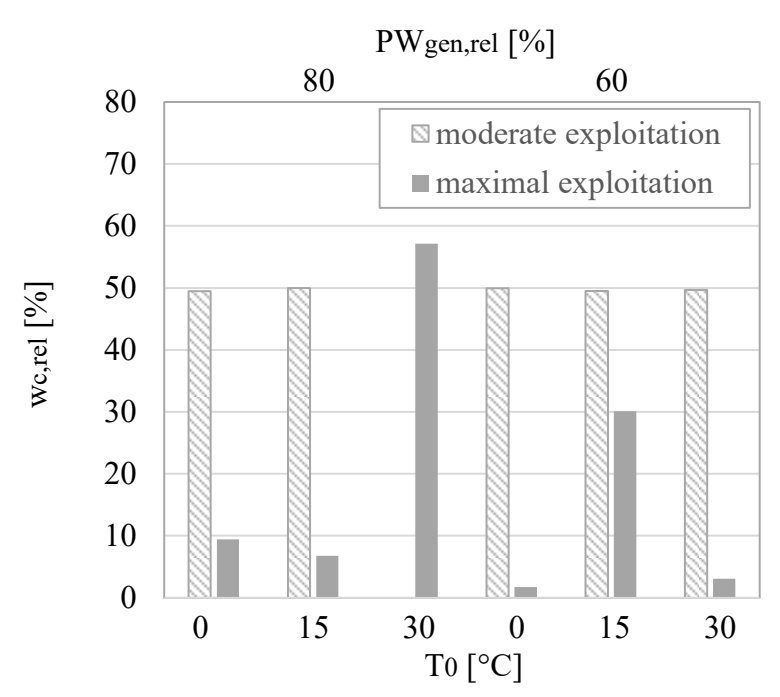

Figure 14 Controlled vane stage two cooling flows, related to uncontrolled operation 


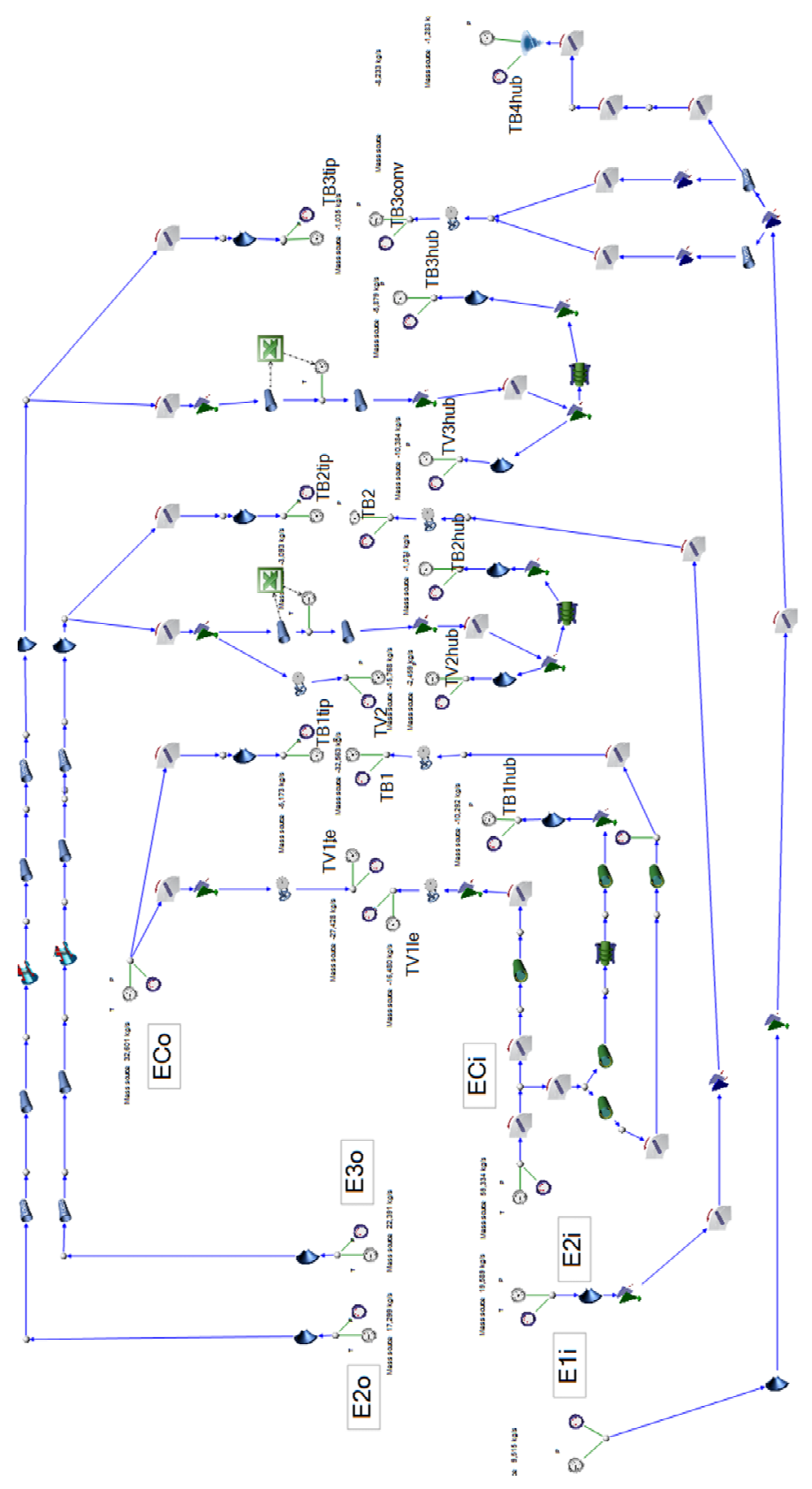

Figure 15 SAS network model in Flownex SE 